\title{
Effect of Low and High Intensity Exercise on Circulating Growth Hormone in Men*
}

\author{
NANCY E. FELSING, JO ANNE BRASEL, AND DAN M. COOPER $\dagger$ \\ Divisions of Respiratory and Critical Care, and Endocrinology, Department of Pediatrics, Harbor-UCLA \\ Medical Center, UCLA School of Medicine, Torrance, California 90509
}

\begin{abstract}
We hypothesized that circulating $\mathrm{GH}$ would increase only if a threshold of work intensity [corresponding to the anerobic or lactate threshold (LT)] was exceeded. Ten healthy male volunteers (18-35 yr) first performed ramp-type progressive cycle-ergometer exercise to determine the LT and the maximal oxygen uptake. On subsequent mornings after an overnight fast, each subject performed bouts of 1,5 , and 10 min constant work rate exercise of either high intensity (above LT) or low intensity (below LT). A 1 -h interval separated exercise bouts. Gas exchange (breath-by-breath), GH, immunoreactive insulin, glucose, lactate, pyruvate, and epinephrine and norepinephrine were measured at regular intervals. After the 10-min bouts of high compared with low intensity exercise, lactate was $7.2 \pm 3.7 \mathrm{mmol} / \mathrm{L}$ vs. $1.4 \pm 1.3, P<$
\end{abstract}

0.05 ; epinephrine was $1,113 \pm 519 \mathrm{pmol} / \mathrm{L}$ vs. $496 \pm 273, P<0.05$; and norepinephrine was $7.89 \pm 3.45 \mathrm{nmole} / \mathrm{L}$ vs. $2.83 \pm 1.34, P<0.05)$. $\mathrm{GH}$ did not increase significantly from preexercise baseline during low intensity exercise (e.g., $\mathrm{GH}$ after 10 -min low intensity exercise changed from baseline values by $1.5 \pm 2.0 \mu \mathrm{g} / \mathrm{L}$, NS). Although lactate was elevated after 5 -min of high intensity exercise, peak GH was significantly elevated (mean increase above baseline of $7.7 \pm 2.4 \mu \mathrm{g} / \mathrm{L}, P<$ 0.05 ) only after $10 \mathrm{~min}$ of high intensity exercise (increases in 9 of 10 subjects). The GH increase occurred despite simultaneous increases in both IRI and glucose. A minimum duration of $10 \mathrm{~min}$, high intensity exercise consistently increased circulating $\mathrm{GH}$ in adult males. $(J \mathrm{Clin}$ Endocrinol Metab 75: 157-162, 1992)
$\mathrm{E}^{\mathrm{x}}$ XERCISE AFFECTS GH secretory patterns, and this GH effect likely plays a role in growth and in the training phenomenon (1-4). The exercise duration or intensity that will elicit a reproducible and substantial GH pulse in humans is not precisely known. There are reasons to believe that the $\mathrm{GH}$ response to increasing work intensity is nonlinear in nature and may be characterized by a threshold. The purpose of this study was to test whether or not a work-intensity threshold could be identified for the GH response.

Although the magnitude of the GH response is related to work intensity (5-8), there is great variability in the reported amplitude and duration of exercise-induced GH response in humans. The variability might be explained by the fact that in previous studies, some subjects exercised below, whereas others worked above a threshold for $\mathrm{GH}$ release. The $\mathrm{GH}$ response may be correlated to the lactate response to exercise (9-11) which increases in a nonlinear manner with work intensity (12). Finally, other stress responses, e.g. circulating catecholamines, are disproportionately elevated during heavy compared to light exercise $(13,14)$. We hypothesized that exercise would elicit a significant $\mathrm{GH}$ pulse only when the work rate exceeded the anaerobic or lactic acid threshold (high intensity exercise). The latter refers to the work rate above which circulating lactic acid increases $(15,16)$.

Table 1 reviews 10 studies of the acute GH response to exercise $(5,17-25)$. It highlights the diversity of approaches

Received September 23, 1991.

Address requests for reprints to: Dan M. Cooper, M.D., N-4, 1000 West Carson Street, Torrance, California 90509.

* This work was supported by USPHS Grants HD-26939 and HL11907 and by General Clinical Research Grant RR-00425.

$\dagger$ Recipient of the Career Investigator Award of the American Lung Association. used to determine exercise intensity. In most studies, the work rate chosen is equivalent to $60-70 \%$ of the subject's maximal oxygen uptake ( $\mathrm{VO}_{2}$ max). By and large, these protocols represent submaximal high intensity exercise since the lactate threshold (LT) occurs between $40-60 \%$ of $\dot{\mathrm{VO}}_{2}$ max in healthy subjects (26). But some of the subjects may have exercised above and others below their LT for the following reasons. Investigators often used predicted rather than measured $\dot{\mathrm{V}} \mathrm{O}_{2} \max$, and most did not measure the LT in individual subjects. This, combined with the large intersubject variability of $\mathrm{VO}_{2}$ max and the LT, may have confounded the investigators' ability to precisely determine work rate intensity.

The duration of the exercise input in previous studies tended to be long (the mean of Table 1 is $44 \mathrm{~min}$ ). In contrast, naturally occurring patterns of activity in adults and children are shorter. Thus, we specifically examined the effects of short bursts of exercise more likcly to mimic physiologically significant patterns of activity.

\section{Subjects and Methods}

\section{Subjects (Table 2)}

Ten healthy adult male volunteers participated in the study. They ranged in age from 18-35 yr old (mean $27 \pm 5 \mathrm{yr}$ ). None of the subjects were smokers, suffered from chronic diseases, or took drugs or medications. None of these individuals trained as competitive athlctes, but most participated in some form of regular exercise. The study was approved by the institutional Human Subjects' Committee, and each participant granted informed consent.

\section{Protocol}

The protocol consisted of three exercise sessions each performed on different days, separated by at least 1 week. On day one each volunteer 
TABLE 1. Representative previous studies of the effect of exercise on circulating GH

\begin{tabular}{|c|c|c|c|c|c|}
\hline Ref. nu. & Yr & $\mathrm{VO}_{2} \max$ & $\begin{array}{l}\text { Lactate thresh- } \\
\text { old }\end{array}$ & Work intensity & $\begin{array}{c}\text { Duration } \\
(\min )\end{array}$ \\
\hline (17) & 1990 & Predicted & Not measured & $66 \% \dot{\mathrm{VO}}_{2} \max$ & 6 \\
\hline (18) & 1990 & Predicted & Not measured & $70 \% \mathrm{VO}_{2} \max$ & 15 \\
\hline (19) & 1990 & Measured & Not measured & $65 \% \dot{\mathrm{VO}}_{2} \max$ & $\sim 90$ \\
\hline$(20)$ & 1990 & Predicted & Not measured & $60 \% \mathrm{VO}_{2} \max$ & 30 \\
\hline (21) & 1989 & Measured & Measured & Equal to LT & $\sim 80$ \\
\hline$(22)$ & 1988 & Measured & Not measured & $70 \% \mathrm{VO}_{2} \max$ & 60 \\
\hline (23) & 1987 & Not measured & Not measured & $\begin{array}{l}1,1.5 \text {, and } 2 \text { watt } / \mathrm{kg} \text { for } \\
5 \text {-min periods }\end{array}$ & 15 \\
\hline (24) & 1986 & Measured & Not measured & $60 \% \mathrm{VO}_{2} \max$ & 60 \\
\hline (5) & 1985 & Measured & Not measured & $\begin{array}{l}63(10 \mathrm{~min}), 86(10 \\
\quad \min ), 100(5-7 \mathrm{~min})\end{array}$ & $\sim 26$ \\
\hline$(25)$ & 1981 & Not measured & Not measured & $55 \mathrm{watt} / \mathrm{m}^{2}$ & 60 \\
\hline
\end{tabular}

TABLE 2. Subject age, weight, height, and exercise gas exchange characteristics

\begin{tabular}{|c|c|c|c|c|c|c|c|c|}
\hline Subject & Age (yr) & $\mathrm{Wt}(\mathrm{Kg})$ & $\mathrm{Ht}(\mathrm{cm})$ & $\begin{array}{c}\mathrm{LT} \\
\left(\% \mathrm{VO}_{2} \max \right)\end{array}$ & $\begin{array}{c}\dot{\mathrm{VO}_{2} \max } \\
(\mathrm{ml} / \mathrm{min} \cdot \mathrm{kg})\end{array}$ & $\begin{array}{c}\mathrm{LT} \\
(\mathrm{ml} / \mathrm{min} \cdot \mathrm{kg})\end{array}$ & $\begin{array}{c}\text { Low WR } \\
\left(\% \dot{\mathrm{VO}}_{2} \max \right)\end{array}$ & $\begin{array}{c}\text { High WR } \\
\left(\% \mathrm{VO}_{2} \max \right)\end{array}$ \\
\hline 1 & 35 & 80 & 178 & 47 & 38 & 18 & 18 & 68 \\
\hline 2 & 24 & 75 & 180 & 59 & 37 & 22 & 24 & 74 \\
\hline 3 & 28 & 86 & 185 & 48 & 49 & 23 & 25 & 75 \\
\hline 4 & 27 & 89 & 185 & 64 & 41 & 26 & 23 & 58 \\
\hline 5 & 32 & 81 & 178 & 70 & 49 & 35 & 26 & 78 \\
\hline 6 & 21 & 81 & 190 & 50 & 43 & 21 & 20 & 69 \\
\hline 7 & 29 & 93 & 196 & 80 & 38 & 30 & 32 & 82 \\
\hline 8 & 18 & 74 & 187 & 54 & 40 & 22 & 24 & 74 \\
\hline 9 & 27 & 58 & 173 & 45 & 46 & 21 & 17 & 68 \\
\hline 10 & 29 & 58 & 170 & 43 & 48 & 21 & 23 & 73 \\
\hline Mean & 27 & 78 & 182 & 56 & 43 & 24 & 23 & 72 \\
\hline SD & 5 & 11 & 8 & 12 & 5 & 5 & 4 & 6 \\
\hline
\end{tabular}

performed progressive ramp-type cycle ergometry to determine the $\mathrm{VO}_{2} \max$ and the LT (see below). The next two sessions consisted of 1-, 5 -, and 10-min of constant work rate exercise on the cycle ergometer. An hour of rest separated each exercise burst. For one session, the work rate chosen corresponded to $50 \%$ of the difference between the subject's LT and $\mathrm{VO}_{2} \max$ (high intensity exercise), whereas for the other session all work rates corresponded to $50 \%$ of the subject's lactate threshold (low intensity).

For a given session, subjects always performed a fixed sequence of exercise duration $(1-, 5-, 10-\mathrm{min})$, but the order of the exercise intensity (i.e. high intensity day, low intensity day) was randomized. We chose this protocol because we anticipated that 10 -min exercise bouts would be the most likely to elicit GH responses and it was performed last to minimize possible confounding effects of a prior GH pulse on subsequent pulses. We chose a 1-h interval between exercise bouts. This was a balance between, on the one hand, allowing sufficient time for gas exchange parameters, lactate, and hormones levels to return to baseline, and, on the other hand, minimizing the possibility of spontaneous $\mathrm{GH}$ pulses and too prolonged a fasting period.

The subjects arrived at approximately $0800 \mathrm{~h}$ on the morning of a low or high intensity exercise study. We chose the morning to perform the study because fewer naturally occurring $\mathrm{GH}$ pulses are seen during the morning hours (after about 0800-0900 h). They were instructed to refrain from any exercise and to remain fasted for at least $12 \mathrm{~h}$ before the study. An antecubital venous catheter was placed for intermittent blood sampling. Baseline blood samples were taken at 10 and $5 \mathrm{~min}$ before the first $(1 \mathrm{~min})$ exercise burst. The subject performed the exercise, then samples were taken every $10 \mathrm{~min}$ during the rest period. This was repeated after the 5 - and 10 -min bursts. An additional sample was obtained during exercise (at $5 \mathrm{~min}$ ) during the last (10-min) cxcrcisc period. Breath-by-breath gas exchange measurements were made $5 \mathrm{~min}$ before, during, and $10 \mathrm{~min}$ after each exercise period.

\section{Gas exchange measurements}

The subjects breathed through a mouthpiece connected to a low impedance turbine volume transducer and a breathing valve with a combined dead space of $90 \mathrm{~mL} . \mathrm{O}_{2}$ and $\mathrm{CO}_{2}$ tensions were determined by mass spectrometry from a sample drawn continuously from the mouthpiece at $1 \mathrm{~mL} / \mathrm{s}$. The inspired and expired volumes and gas tension signals underwent analog-to-digital conversion, from which oxygen uptake $\left(\mathrm{VO}_{2}\right)$ (standard temperature pressure dry), $\mathrm{CO}_{2}$ production $\left(\mathrm{VCO}_{2}\right)$ (standard temperature pressure dry), and minute ventilation $\left(\dot{\mathrm{V}}_{\mathrm{E}}\right)$ (body temperature pressure saturated) were calculated on-line, breathby-breath as previously described $(27)$. The breath-by-breath data were then interpolated to $1-\mathrm{s}$ time intervals.

\section{Noninuasive determination of $L T$ and $\dot{V} O_{2}$ max}

The LT and $\dot{\mathrm{O}}_{2}$ max were measured noninvasively from the gas exchange data obtained during the progressive exercise. The lactate threshold was defined as the $\mathrm{VO}_{2}$ at which the ventilatory equivalent for $\mathrm{O}_{2}\left(\dot{\mathrm{V}}_{\mathrm{E}} / \dot{\mathrm{VO}}_{2}\right)$ and the end tidal $\mathrm{O}_{2}\left(\mathrm{PetO}_{2}\right)$ increased without an increase in the ventilatory equivalent for $\mathrm{CO}_{2}\left(\dot{\mathrm{V}}_{\mathrm{E}} / \mathrm{VCO}_{2}\right)$ and the end tidal $\mathrm{CO} 2\left(\mathrm{PetCO}_{2}\right)(28)$. $\dot{\mathrm{VO}}_{2} \mathrm{max}$ was defined as the highest $\dot{\mathrm{VO}}_{2}$ achieved by the subject.

\section{$G H$, glucose, insulin, lactate, and catecholamines}

An in-house RIA was used to measure GH using WHO standard no. $66 / 217$, antisera generated in-house, and hGH from NIDDK for iodination purposes. The GH intraassay variability is less than $10 \%$, interassay variability is $12.6 \%$, and the sensitivity is $0.5 \mu \mathrm{g} / \mathrm{L}$. Insulin was also measured using an in-house RIA using standard from Wellcome cquated to first IRP 66/304, antiporcine antibody from ICN and porcine insulin from Lilly for iodination. The insulin intraassay variability is less than $10 \%$, interassay variability is $11.5 \%$, and the sensitivity $7 \mathrm{pmol} / \mathrm{L}$. Glucose was measured using the Abbott bichromatic analyzer using the Abbott UV glucose kit. The glucose intraassay variability is $2.1 \%$ and the interassay variability is $2.4 \%$. Lactate was measured spectrophotometrically using the Behring Stat-pack rapid lactate test. The lactate intraassay variability is $2.8 \%$, the interassay variability is $3.5 \%$, and the 
sensitivity is $0.55 \mathrm{mmol} / \mathrm{L}$. Pyruvate was measured enzymatically using the Perkin Elmer luminescence spectrophotometer. Pyruvate intraassay variability is $4 \%$ and interassay variability is $12 \%$. Catecholamines [norepinephrine $(\mathrm{NE})$, epinephrine $(\mathrm{E})$ ] were measured by the radioenzymatic method. For NE the intraassay variability is less than $10 \%$ and the interassay variability is $10.6 \%$, and the sensitivity is $0.12 \mathrm{nmol} / \mathrm{L}$. For $\mathrm{E}$ the intraassay variability is less than $10 \%$, interassay is $14.6 \%$, and the sensitivity is $109 \mathrm{pmol} / \mathrm{L}$

\section{Statistical analysis}

Repeated measures analysis of variance was used to describe the patterns of the multiple samples of $\mathrm{GH}$, other hormones, and substrates. Separate analyses were performed for the preexercise values, the peak value, and the $\Delta$ (i.e. the difference between peak and preexercise values). The preexercise values were taken as the level of hormone or substrate immediately before the 1-, 5-, or 10-min exercise bout. When analysis of variance (ANOVA) was found to be significant, Duncan's Multiple Range test was used to determine intergroup significance. Unless otherwise stated, values are presented as mean \pm SD. A $P$ value less than 0.05 was considered significant.

\section{Results}

\section{Gas exchange parameters}

The individual subject age, weight, height, and exercise gas exchange characteristics are shown in Table 2. As expected, the $\mathrm{VO}_{2}$ reached a steady state during the 5- and 10min low intensity exercise bouts but not for high intensity exercise (Fig. 1). $\mathrm{VO}_{2}$, of course, increased significantly with exercise duration for both low and high intensity exercise. With 10 min of exercise, the peak $\mathrm{VO}_{2}$ was 4 and 9 times greater, on average, than baseline for low and high intensity exercise, respectively.

\section{Lactate and pyruvate (Fig. 2)}

As expected, lactate concentrations were increased during all durations of high intensity exercise. There were no substantial differences between the two baseline lactate values; however, the lactate levels immediately before the 10 -min high intensity exercise bout were slightly but significantly higher $(P<0.01)$ than the baseline levels and than those before the 5 -min exercise bouts. The coefficient of variation

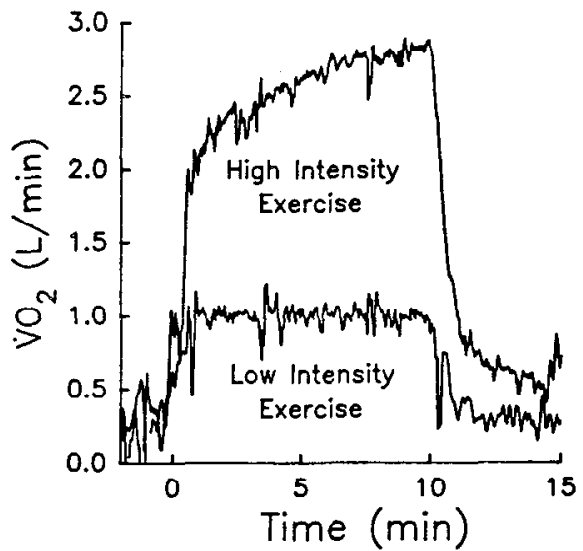

FIG. 1. $\mathrm{V}_{2}$ during low and high intensity exercise in a representative subject. Note that $\mathrm{VO}_{2}$ did not achieve a steady state during high intensity (above LT) exercise even though the work rate was constant.

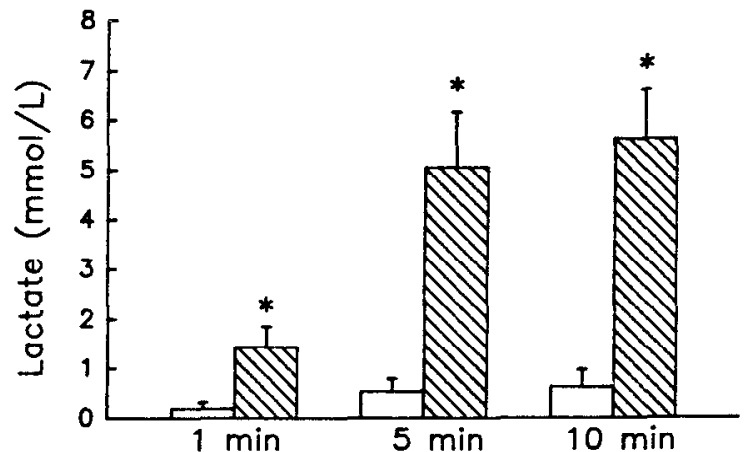

FIG. 2. Mean peak serum lactate levels (minus baseline) and SE after 1,5 , and $10 \mathrm{~min}$ of low (hollow bars) and high (hatched bars) intensity exercise. * indicates $P<0.05$.

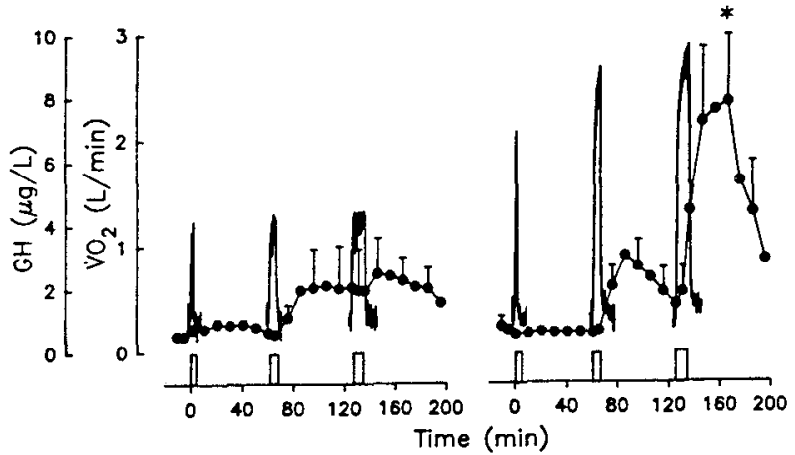

FIG. 3. Mean GH and SE (closed circles) and $\dot{\mathrm{V}}_{2}$ (lines) after 1, 5 , and $10 \mathrm{~min}$ of low (left panel) and high (right panel) intensity exercise. * indicates $P<0.05$. Clear vertical bars represent the exercise bouts. GH significantly increased only after $10 \mathrm{~min}$ of high intensity exercise.

for peak lactate among the subjects was $57 \%$. Qualitatively similar results were found for the lactate-to-pyruvate ratios.

\section{GH (Fig. 3)}

Spontaneous GH pulses (judged by inordinately elevated preexercise $\mathrm{GH}$ with patterns suggesting upward or downward slopes) occurred in only one subject. There were no significant differences between the two baseline $\mathrm{GH}$ levels. $\mathrm{GH}$ responses to exercise were quite variable in magnitude among the subjects; the ratio of peak pulse to baseline ranged from 0.7 to 14 after low intensity exercise and from 0.5 to 51 after high intensity exercise. After low intensity exercise, exercise-associated increases in GH for the group as a whole were not statistically significant. Two of the 10 subjects had disproportionately greater $\mathrm{GH}$ pulses than the others and their $\mathrm{GH}$ pulses account by and large for the increase in the mean GH concentration after 5 and $10 \mathrm{~min}$ of exercise. After the $10-\mathrm{min}$ high intensity bout there was a significant $\mathrm{GH}$ pulse in 9 of 10 subjects (mean peak of $7.7 \pm 2.4 \mu \mathrm{g} / \mathrm{L} v \mathrm{~s}$. a mean baseline of $1.7 \pm 2.4 \mu \mathrm{g} / \mathrm{L}, P<0.05$ ). The small increase in $\mathrm{GH}$ after 5-min of high intensity exercise was not statistically significant. The coefficient of variation for the peak GH pulse after $10 \mathrm{~min}$ in the high intensity range was $85 \%$. After the 10-min high intensity exercise bout, the peak GH pulse occurred at a mean of $29 \pm 12 \mathrm{~min}$ after the onset of exercise and occurred significantly $(P<0.05)$ later than those 
of lactate (15 min), E (10 min), NE (11 min), and insulin (21 $\min$ ).

\section{Glucose and insulin (Fig. 4)}

After low intensity exercise, glucose increased by $0.39 \pm$ $0.11 \mathrm{mmol} / \mathrm{L}(P<0.05)$ for 5 -min exercise and by $0.28 \pm$ $0.11 \mathrm{mmol} / \mathrm{L}$ for 10 -min bouts. With high intensity exercise, significant increases $(P<0.05)$ were found after the 1 -min $(0.28 \pm 0.06 \mathrm{mmol} / \mathrm{L}), 5-\mathrm{min}(0.39 \pm 0.11 \mathrm{mmol} / \mathrm{L})$, and $10-$ $\min (0.61 \pm 0.11 \mathrm{mmol} / \mathrm{L})$ protocols. Low intensity exercise had no significant effect on insulin. During high intensity exercise, insulin increased significantly $(P<0.05)$ after the $1-\min (29 \pm 7 \mathrm{pmol} / \mathrm{L}), 5-\mathrm{min}(50 \pm 14 \mathrm{pmol} / \mathrm{L})$, and $10-$ $\min (29 \pm 7 \mathrm{pmol} / \mathrm{L})$ protocols.

\section{Catecholamines (Fig. 5)}

During low intensity protocols, significant increases were found for $\mathrm{E}$ after the 10-min exercise bout and for NE after the 1- and 10-min bouts. Both $\mathrm{E}$ and NE increased with the high intensity protocols after the 5- and 10-min bouts. The magnitude of the increase in catecholamines after low intensity was substantially less than that observed after the high intensity protocols. The coefficient of variation for peak NE among the subjects was $45 \%$ and for epinephrine was $49 \%$.

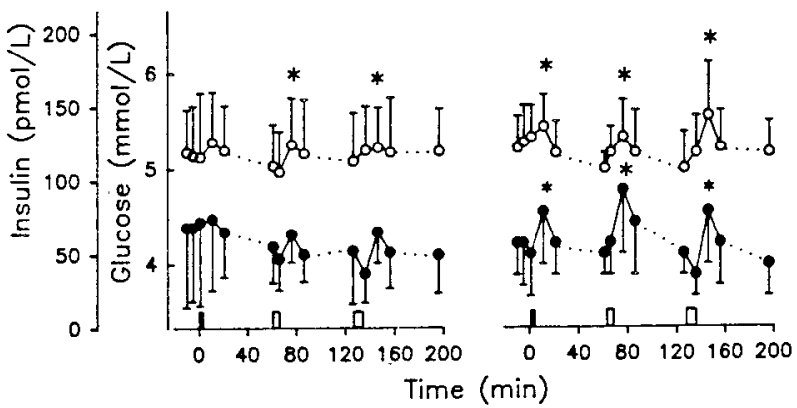

Fig. 4. Mean glucose and SE (open circles) and mean insulin and SE (closed circles) after 1,5, and $10 \mathrm{~min}$ of low (left panel) and high (right panel) intensity exercise. ${ }^{*}$ indicates $P<0.05$ for peak over baseline values. Clear vertical bars represent the exercise bouts. Both insulin and glucose increased consistently after high intensity exercise.
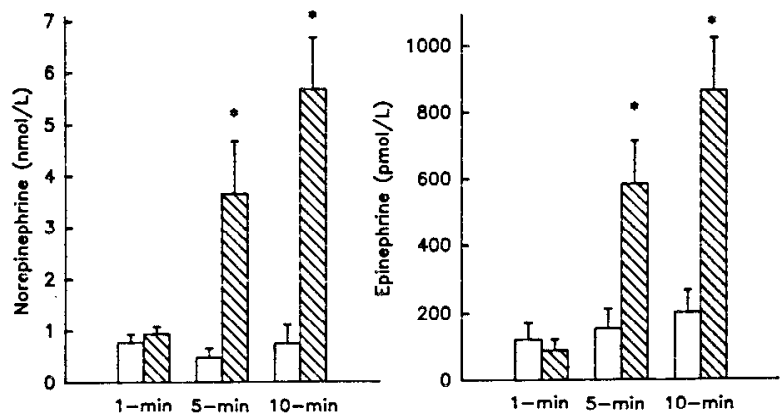

FIG. 5. Mean peak values (minus baseline) \pm SE for NE (left panel) and $\mathrm{E}$ (right panel) after 1, 5, and $10 \mathrm{~min}$ of low (hollow bars) and high (hatched bars) intensity exercise. * indicates $P<0.05$ compared to low intensity exercise.

\section{Discussion}

The gas exchange and lactate data demonstrate that we achieved the goal of identifying low- and high-intensity exercise in the subjects. The $10-$ min period of high-intensity (above the lactate threshold) exercise consistently resulted in bursts of $\mathrm{GH}$ secretion in adult males. In contrast, low intensity exercise, including the 10 -min protocols, did not elicit significant GH responses. Despite rigorous control over the work rate, our data, like most previous studies, revealed great subject-to-subject variability in the peak $\mathrm{GH}$ response achieved (n.b., the coefficient of variation among the subjects was higher for $\mathrm{GH}$ than for lactate and catecholamines). Thus, whereas there does appear to be a minimum threshold of exercise duration and intensity necessary for a $\mathrm{GH}$ pulse, exercise intensity alone cannot entirely predict the amplitude and duration of the subsequent $\mathrm{GH}$ response.

The onset of the GH response to exercise was later and less consistent than the gas exchange, lactate, and other hormonal responses. The elevation in $\mathrm{GH}$ induced by exercise lasted far longer than both the 10-min exercise bout itself and the other substrate and hormonal responses studied. The time required to achieve a $\mathrm{GH}$ response in our study, between 5 and $10 \mathrm{~min}$, was similar to that observed by Sutton and Lazarus (9) who used a 20-min protocol. The peak $\mathrm{GH}$ in their study also occurred at about $30 \mathrm{~min}$ after the onset of exercise, i.e. after the exercise bout was completed. It appears that $10 \mathrm{~min}$ of high intensity exercise are necessary to reliably stimulate pituitary secretion of $\mathrm{GH}$.

The disappearance of $\mathrm{GH}$ from the circulation follows a first-order exponential decay (29-32), and reported halftimes range from $8.9 \mathrm{~min}(30)$ to as high as $27 \mathrm{~min}(32)$. A variety of techniques, including deconvolutional analysis (29, 33), has been used to quantify pituitary GH secretion during spontaneous pulses. We constructed a simple single compartment model in which GH is transported from the pituitary to the circulation with first-order kinetics, and follows a first-order disappearance from the plasma. Iterative nonlinear curve-fitting techniques (34) were used to calculate the time constants and the amount of $\mathrm{GH}$ secreted from the mean $\mathrm{GH}$ levels during and after the 10-min high intensity protocol. The following equation was used:

$$
\mathrm{y}=\mathrm{A} \cdot\left[\mathrm{e}^{-\mathrm{t} / \tau_{1}}-\mathrm{e}^{\left(-t\left(1 / \tau_{1}+1 / \tau_{2}\right)\right.}\right]
$$

where A represents the $\mathrm{GH}$ released consequent to the exercise stimulus, $\tau_{1}$ corresponds to the disappearance time constant (equivalent to the half-time divided by 0.69 ) for $\mathrm{GH}$ from the plasma compartment, $\tau_{2}$ corresponds to the time constant of $\mathrm{GH}$ release from the pituitary compartment to the plasma, and $t$ is the time in min. (A 5min delay was included in the model).

A reasonably good fit was seen when 27 min was used as the value for the half-time of plasma GH disappearance (Fig. 6). The analysis predicted a total GH pulse of 0.061 $\mathrm{mg}$ when using the mean weight of our subjects $(78 \mathrm{~kg})$ and a GH volume of distribution of $4.4 \%$ (35). The model suggests a $t^{1 / 2}$ of the $\mathrm{GH}$ relcase into the plasma of $11 \pm$ $3 \mathrm{~min}$, and a mean GH secretory rate over four half-lives 


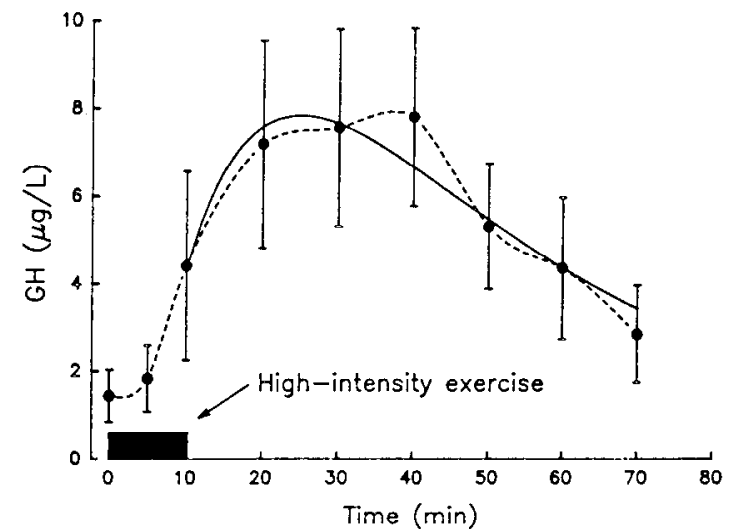

FIG. 6. Mean \pm SE for GH (closed circles) during and after 10 min of high intensity exercise. The dashed line is a cubic splines best-fit curve for the GH data. The solid line is the best fit curve for the exponential model as described in the text.

of $0.41 \mu \mathrm{g} / \mathrm{L} \cdot \mathrm{min}$, a value comparable in magnitude to those found from spontaneous pulses (36).

The data show that the GH response to exercise likely has a different mechanism than other known physiological stimuli. Hypoglycemia and/or rapid falls in glucose concentration, for example, cause $\mathrm{GH}$ release (37), but, as shown in Fig. 4, subjects remained euglycemic and glucose concentrations tended to increase. Classically, insulin can be used to stimulate GH by inducing hypoglycemia. In our studies, insulin increased significantly following short bursts of high intensity exercise with no evidence of hypoglycemia. It has been reported that insulin decreases during long term exercise (e.g. greater than 40 $\min )(38)$, but recent data in human subjects during and after short term high intensity exercise demonstrate either no change or, consistent with our results, increases in plasma insulin (39-41). In addition, both insulin and GH were increasing simultaneously following exercise (peak insulin occurred at $21 \mathrm{~min}$; peak $\mathrm{GH}$ at $29 \mathrm{~min}$ ). It would be difficult to conclude from these observations that insulin either directly or indirectly stimulated the exerciseinduced GH pulses.

Both $\mathrm{E}$ and NE were significantly elevated after both 5- and 10-min of high intensity exercise, while GH was significantly elevated only after 10-min high-intensity exercise. The $E$ and NE responses reflect alterations in neuroadrenergic control known to occur during graded exercise $(42,43)$; namely, a reduction in parasympathetic tone, an increase in sympathetic tone, and stimulus of adrenal production of epinephrine. The discrepancy between the $\mathrm{GH}$ and catecholamine responses, therefore, suggests that neuroadrenergic inputs to the hypothalamus or the pituitary, i.e. stress, are not the only modulators of the exercise-associated GH response.

There is mounting evidence to support the idea that exercise-induced GH is important in somatic growth and in the effect of physical training on muscles. Borer et al.
(44) demonstrated that exercising hamsters grew at faster rates than did sedentary animals, and the exercising animals had greater frequency and amplitude of spontaneous GH pulses. More recently, Grindeland et al. (1) studied the effect of exercise and administration of exogenous $\mathrm{GH}$ on muscle growth in hypophysectomized rats recovering from hindlimb suspension. Their preliminary data show that the most marked increases in muscle mass occurred with the combination of exercise and GH. In contrast, the training effect in humans can occur with exercise protocols that are above or below the subject's lactate threshold (45); and DeVol and co-workers (46) showed that training induced muscle hypertrophy with increases in muscle tissue insulin-like growth factor-I messenger RNA cven in hypophysectomized animals. Apparently, the growth and hypertrophy observed in response to exercise is modulated by both $\mathrm{GH}$-dependent and $\mathrm{GH}$-independent processes.

Ten minutes of constant work rate, high intensity exercise is a minimum stimulus for consistent GH release in adult males. Whether or not such patterns of activity represent naturally occurring, physiologically important $\mathrm{GH}$ stimuli remains unknown. It is intriguing that the character of the exercise stimulus may be as important as the total work done in eliciting the GH response. Vanhelder et al. (7) demonstrated that a series of 1-min bursts of very high intensity exercise resulted in a greater $\mathrm{GH}$ response than constant work rate exercise $(20 \mathrm{~min})$ in which the work expenditure and duration of the two protocols were the same. The importance of the pattern of exercise is highlighted by recent findings that the pulsatile nature of $\mathrm{GH}$ release may optimize its overall effect on growth (47). Finally, our data add to the body of evidence that GH pulses in response to exercise, unlike spontaneous GH pulses, are accompanied by increases in other tissue growth mediators (insulin, catecholamines). Perhaps this hormonal "milieu" is as important to growth and training as is the elevation in GH itself.

\section{References}

1. Grindeland RE, Roy R, Edgerton VR, et al. 1991 Exercise and growth hormone have synergistic effects on skeletal muscle and tibias of suspended rats [Abstract]. FASEB J. 5:A1037.

2. Borer KT. 1980 Characteristics of growth-inducing exercise. Physiol Behav. 24:713-720.

3. Kelly PJ, Eisman JA, Stuart MC, Pocock NA, Sambrook PN, Gwinn TH. 1990 Somatomedin-C, physical fitness, and bone den sity. J Clin Endocrinol Metab. 70:718-23.

4. Poehlman ET, Copeland KC. 1990 Influence of physical activity on insulin-like growth factor-I in healthy younger and older men. J Clin Endocrinol Metab. 71:1468-73.

5. Naveri H. 1985 Blood hormone and metabolic levels during graded cycle ergometer exercise. Scand J Lab Clin Invest. 45:599-603.

6. VanHelder WP, Casey K, Goode RC, Radomski WM. 1986 Growth hormone regulation in two types of aerobic exercise of equal oxygen uptake. Eur J Appl Physiol. 55:236-9.

7. VanHelder WP, Goode RC, Radomski MW. 1984 Effect of anaer- 
obic and aerobic exercise of equal duration and work expenditure on plasma growth hormone levels. Eur J Appl Physiol. 52:255-7.

8. Lassarre C, Girard F, Durand J, Raynaud J. 1974 Kinetics of human growth hormone during submaximal exercise. J Appl Physiol. $37: 826-30$.

9. Sutton I, Lazarus L. 1976 Growth hormone in exercise: comparison of physiological and pharmacological stimuli. J Appl Physiol. 41:523-7.

10. Sutton JR. 1977 Effect of acute hypoxia on the hormonal response to exercise. J Appl Physiol. 42:587-92.

11. VanHelder WP, Radomski MW, Goode RC, Casey K. 1985 Hormonal and metabolic response to three types of exercise of equal duration and external work output. Eur J Appl Physiol. 54:337-42.

12. Astrand P-O, Rodahl K. 1977 Textbook of work physiology, 2nd ed. New York: McGraw-Hill; 389.

13. Cooper DM, Barstow TJ, Bergner A, Lee W-NP. 1989 Blood glucose turnover during high- and low-intensity exercise. Am J Physiol. 257:405-12.

14. Cooper DM, Wasserman DH, Vranic M, Wasserman K. 1986 Glucose turnover in response to exercise during high- and low- $\mathrm{FiO}_{2}$ breathing in man. Am J Physiol. 251:E209-14.

15. Wasserman K, Whipp BJ, Koyal SN, Beaver WL. 1973 Anaerobic threshold and respiratory gas exchange during exercise. I Appl Physiol. 35:236-43.

16. Wasserman K, Whipp BJ, Davis JA. 1981 Respiratory physiology of exercise: metabolism, gas exchange, and ventilatory control. In: Widdicombe JG, ed. Respiratory Physiology III. (Int. Rev. Physiol. Ser., vol. 23.) Baltimore: University Park Press.

17. Amirav I, Dowdeswell RJ, Plit M, Panz VR, Joffe VI, Seftel HC. 1990 Growth hormone response to exercise in asthmatic and normal children. Eur J Pediatr. 149:443-6.

18. Seip RL, Weltman A, Goodman D, Rogol AD. 1990 Clinical utility of cycle exercise for the physiologic assessment of growth hormone release in children. Am J Dis Child. 144:998-1000.

19. Tarnopolsky LJ, MacDougall JD, Atkinson SA, Tarnopolsky MA, Sutton JR. 1990 Gender differences in substrate for endurance exercise. J Appl Physiol. 68:302-8.

20. Bang P, Brandt J, Degerblad M, et al. 1990 Exercise-induced changes in insulin-like growth factors and their low molecular weight binding protein in healthy subjects and patients with growth hormone deficiency. Eur J Clin Invest. 20:285-92.

21. Friedmann B, Kindermann W. 1989 Energy metabolism and regulatory hormones in women and man during endurance exercise. Eur J Appl Physiol. 59:1-9.

22. Hagberg JM, Seals DR, Yerg JE, et al. 1988 Metabolic responses to exercise in young and older athletes and sedentary men. J Appl Physiol. 65:900-8.

23. Greene SA, Torresani T, Prader A. 1987 Growth hormone response to a standardised exercise test in relation to puberty and stature. Arch Dis Child. 62:53-6.

24. Bunt JC, Boileau RA, Bahr JM, Nelson RA. 1986 Sex and training differences in human growth hormone levels during prolonged exercise. J Appl Physiol. 61:1796-1801.

25. Raynaud J, Drouet L, Martineaud J-P, Bordachar J, Coudert J, Durand J. 1981 Time course of plasma growth hormone during exercise in humans at altitude. J Appl Physiol. 50:229-33.

26. Wasserman K, Hansen JE, Sue DY, Whipp BJ. 1987 Principles of exercise testing and interpretation. Philadelphia: Lea \& Febiger.

27. Beaver WL, Lamarra N, Wasserman K. 1981 Breath-by-breath measurement of true alveolar gas exchange. J Appl Physiol. $51: 1662-75$

28. Whipp BJ, Davis JA, Torres F, Wasserman K. 1981 A test to determine parameters of aerobic function during exercise. J Appl Physiol. 50:217-21.

29. Hindmarsh PC, Matthews DR, Brain C, Pringle PJ, Brook CG. 1990 The application of deconvolution analysis to elucidate the pulsatile nature of growth hormone secretion using a variable halflife of growth hormone. Clin Endocrinol (Oxf). 32:739-47.

30. Hindmarsh PC, Matthews DR, Brain CE, et al. 1989 The half-life of exogenous growth hormone after suppression of endogenous growth hormone secretion with somatostatin. Clinical Endocrinol (Oxf). 30:443-50.

31. Cameron DP, Burger HG, Catt KJ, Doig A. 1969 Metabolic clearance rate of radioiodinated human growth hormone in man. J Clin Invest. 48:1600-8.

32. Parker ML, Utiger RD, Daughaday WH. 1962 Studies of human growth hormone. II. The physiologic disposition and metabolic fate of human growth hormone in man. J Clin Invest. 41:262-8.

33. Veldhuis JD, Iranmanesh A, Ho KK, Waters MJ, Johnson ML, Lizarralde G. 1991 Dual defects in pulsatile growth hormone secretion and clearance subserve the hyposomatotropism of obesity in man. J Clin Endocrinol Metab. 72:51-9.

34. Jennrich R. 1988 Nonlinear regression. In: Dixon WJ, ed. BMDP statistical software manual. Berkeley: University of California Press; $857-84$.

35. Albertsson Wikland K, Rosberg S, Libre E, Lundberg LO, Groth T. 1989 Growth hormone secretory rates in children as estimated by deconvolution analysis of 24 -h plasma concentration profiles. Am J Physiol. 257:E809-14

36. Iranmanesh A, Lizarralde G, Johnson ML, Veldhuis JD. 1991 Nature of altered growth hormone secretion in hyperthyroidism. J Clin Endocrinol Metab. 72:108-15.

37. Roth J, Glick SM, Yalow RS. 1963 Hypoglycemia: a potent stimulus to the secretion of growth hormone. Science. 140:987-8.

38. Wasserman DH, Cherrington AD. 1991 Hepatic fuel metabolism during muscular work: role and regulation. Am J Physiol. 260:E81124.

39. Laso FJ, Gonzalez Buitrago JM, Martin Ruiz C, de Castro S. 1991 Hormonal regulation of potassium shifts during graded exhausting exercise. Eur J Appl Physiol. 62:292-6.

40. Lavoie JM, Bonneau MC, Roy JY, Brisson GR, Helie R. 1987 Effects of dietary manipulations on blood glucose and hormonal responses following supramaximal exercise. Eur J Appl Physiol. 56:109-14.

41. Yale JF, Leiter LA, Marliss EB. 1989 Metabolic responses to intense exercise in lean and obese subjects. J Clin Endocrinol Metab. 68:43845.

42. Savin W, Davidson D, Haskell WL. 1982 Autonomic contribution to heart rate recovery from exercise in humans. J Appl Physiol. 53:1572-5.

43. Darr K, Basset D, Morgan B, Thomas DP. 1988 Effects of age and training status of heart rate recovery after peak exercise. Am I Physiol. 254:H340-3.

44. Borer KT, Shapiro B, Vinik AI. 1983 A role for somatostatin in the control of hamster growth. Brain Res Bull. 11:663-9.

45. Barstow TJ, Casaburi R, Storer T. 1989 Training speeds kinetics of VO2 for work below the lactate threshold. FASEB J. 3:A849.

46. DeVol DL, Rotwein P, Sadow JL, Novakofski J, Bechtel PJ. 1990 Activation of insulin-like growth factor gene expression during work-induced skeletal muscle growth. Am J Physiol. 259:E89-95.

47. Maiter D, Underwood LE, Maes M, Davenport ML, Ketelslegers JM. 1988 Different effects of intermittent and continuous growth hormone $(\mathrm{GH})$ administration on serum somatomedin-C/insulinlike growth factor I and liver GH receptors in hypophysectomized rats. Endocrinology 123:1053-9. 